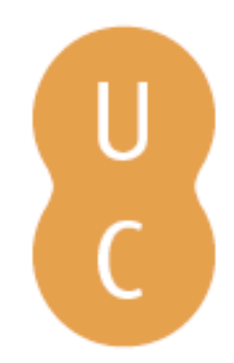

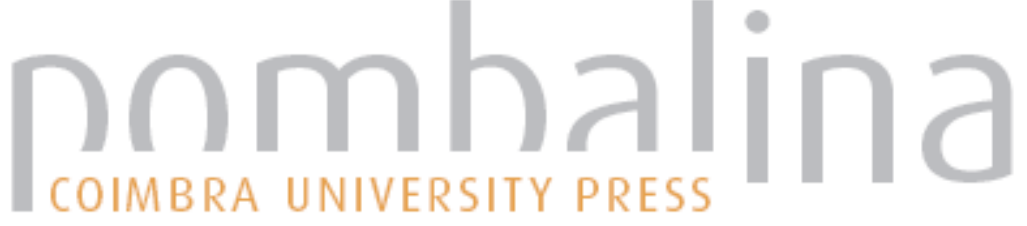

\section{As sonatas para teclado de Carlos Seixas interpretadas ao piano}

Autor(es): $\quad$ Martins, José Eduardo

Publicado por: Imprensa da Universidade de Coimbra

URL

persistente: URI:http://hdl.handle.net/10316.2/32518

DOI: $\quad$ DOI:http://dx.doi.org/10.14195/978-989-26-0409-1_6

Accessed : $\quad$ 26-Apr-2023 09:32:04

A navegação consulta e descarregamento dos títulos inseridos nas Bibliotecas Digitais UC Digitalis, UC Pombalina e UC Impactum, pressupõem a aceitação plena e sem reservas dos Termos e Condições de Uso destas Bibliotecas Digitais, disponíveis em https://digitalis.uc.pt/pt-pt/termos.

Conforme exposto nos referidos Termos e Condições de Uso, o descarregamento de títulos de acesso restrito requer uma licença válida de autorização devendo o utilizador aceder ao(s) documento(s) a partir de um endereço de IP da instituição detentora da supramencionada licença.

Ao utilizador é apenas permitido o descarregamento para uso pessoal, pelo que o emprego do(s) título(s) descarregado(s) para outro fim, designadamente comercial, carece de autorização do respetivo autor ou editor da obra.

Na medida em que todas as obras da UC Digitalis se encontram protegidas pelo Código do Direito de Autor e Direitos Conexos e demais legislação aplicável, toda a cópia, parcial ou total, deste documento, nos casos em que é legalmente admitida, deverá conter ou fazer-se acompanhar por este aviso.

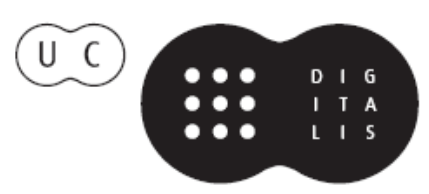




\section{J. M. PEDROSA CARDOSO}

Coordenação

J. M. PEDROSA CARDOSO • ANTÓNIO FILIPE PIMENTEL MANUEL CARLOS DE BRITO • JOSÉ LÓPEZ-CALO JOSÉ EDUARDO MARTINS • ABÍLIO QUEIRÓS

Autores

\section{Carlos Seixas, \\ de Coimbra}

Ano Seixas

Exposição Documental

Coimbra I mprensa da Universidade $\quad 2004$ 
(Página deixada propositadamente em branco) 
J. M. PEDROSA CARDOSO

Coordenação

J. M. PEDROSA CARDOSO • ANTÓNIO FLLIPE PIMENTEL

MANUEL CARLOS DE BRITO • JOSÉ LÓPEZ-CALO

JOSÉ EDUARDO MARTINS • ABÍLIO QUEIRÓS

Autores

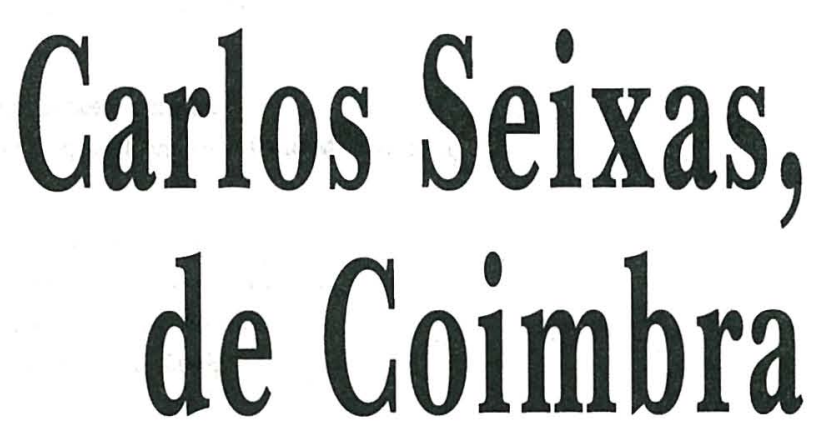

Ano Seixas

Exposição Documental

Coimbra - Imprensa da Universidade $\quad 2004$ 


\section{Coordenação editorial}

Imprensa da Universidade de Coimbra

\section{Concepção gráfica}

António Barros

\section{Paginação}

Victor Hugo Fernandes

\section{Créditos fotográficos}

p. 98 José Manuel Vasconcellos, p. 99 e 100 Varela Pécurto

\section{Execução gráfica}

Imprensa de Coimbra, Lda.

Couraça dos Apóstolos, 126

3000-372 Coimbra

\section{ISBN}

972-8704-33-X

\section{Depósito Legal}

\section{$218421 / 04$}

(C) 2004, Imprensa da Universidade de Coimbra

Obra publicada com o patocínio do GRUPO AMORIM:

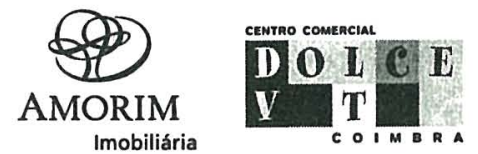

Apoio de:

Reitoria da Universidade de Coimbra

Biblioteca da Universidade de Coimbra

Arquivo da Universidade de Coimbra

Faculdade de Letras da Universidade de Coimbra 
As sonatas para teclado de Carlos Seixas

INTERPRETADAS AO PIANO

\author{
José Eduardo Martins \\ (Universidade de São Paulo)
}

Carlos Seixas é uma figura sui generis na tecladística européia do início do século XVIII. Fatores vários, que estão sendo tratados neste Colóquio, imprimem à parcela considerável da produção para instrumentos de teclado de Carlos Seixas valores outros, a de seus ilustres coetâneos, quer pela maneira do emprego de materiais e até mesmo por determinadas ousadias escriturais. Poder-se-ia considerar que nas 105 Sonatas para instrumentos de tecla transcritas por Macário Santiago Kastner e publicadas pela Fundação Gulbenkian na coleção Portugaliae Musica em 1980 e 1992, assim como nas outras Sonatas atualmente a ele atribuídas, há certa desigualdade no conteúdo, mas a maioria dessa importante criação pode equiparar-se às melhores obras para cravo escritas por Jean-Philippe Rameau (1683-1764), Johan Sebastian Bach (1685-1750), Georg Friedrich Haëndel (1685-1759), Domenico Scarlatti (1685-1757) e alguns importantes compositores do período. Há que se considerar que Carlos Seixas (1704-1742) nasceu cerca de 20 anos mais tarde que os autores citados, precedendo-os alguns lustros na morte.

Alguns fatores foram preponderantes no sentido do reconhecimento tardio da produção para instrumentos de tecla de Carlos Seixas. Poder-se-iam citar determinantes geopolíticas que durante séculos caracterizaram a prevalência de culturas às outras e entre estas aflora o "isolamento" de Portugal ao que se fazia musicalmente em França, Alemanha e Itália como um 
todo, tornando os contatos existentes escassos e pessoais. Acrescente-se o espírito sedentário de Carlos Seixas que, ao que consta, não ultrapassou as fronteiras geográficas de Portugal, assim como a comparação pejorativa que marcou e rotulou tantos autores no passado e que não foi diferente com o compositor de Coimbra, exemplificado como o Scarlatti português.

Felizmente, para cada autor de qualidade, não divulgado, sempre houve o redescobridor exemplar: Johan Sebastian Bach teve em Mendelssohn um divulgador competente, Jean-Philippe Rameau encontrou em Saint-Saëns um entusiasta, e Domenico Scarlatti foi melhor conhecido após a catalogação e edição empreendida por Alexandre Longo. Há incontáveis exemplos mais. Muitos dos "redescobertos" tiveram a divulgação lenta. Quanto a Carlos Seixas, deve-se ao cravista e musicólogo Macário Santiago Kastner o mérito dessa busca abissal às fontes primárias e às outras fontes. Seguindo o caminho aberto por Kastner, musicólogos de expressão têm encontrado e estudado manuscritos para instrumentos de tecla do ilustre conimbricense.

Seria possível admitir que as primeiras edições da obra de Carlos Seixas para teclado, estudadas e transcritas por Kastner para a Casa Schott em 1935 e 1950, tivessem, àquela altura, levado aos vários cantos do mundo as sementes seixianas, mercê do prestígio internacional da editora. Se, sob um prisma, essas edições foram freqüentadas por cravistas, não se descarte a presença vigorosa, entre os pianistas, de Felicja Blumental que, entre tantos méritos, gravou Sonatas de Seixas e de outros autores portugueses do período a partir do trabalho de Kastner. O ilustre musicólogo e cravista escreveria em Fevereiro de 1955 à Blumental, em dedicatória manuscrita fixada na partitura de estudo da pianista: "Eu fiquei encantado ao encontrar em Felicja Blumental a maravilhosa intérprete dos cravistas portugueses, e que interpreta essa música com o verdadeiro sentido estilístico, tocando com alma e grande compreensão do som e da proporção”. Graças às gravações de Blumental em Lps, de alguns cravistas portugueses, majoritariamente Carlos Seixas, hoje remasterizadas em CDs, Sonatas e Tocatas do período em questão compostas em Portugal tornaram-se conhecidas por pianistas, intérpretes da música para teclado consagrada da primeira metade do século XVIII.

Seria possível constatar que Felicja Blumental, em suas interpretações, simplesmente aplica analogicamente, frise-se, com a maior competência, os princípios básicos da transferência de todo o repertório cravista para o pianoforte, inicialmente, e após para o piano. Saliente-se que Kastner, cravista, 
ao entender que Blumental interpretava os tecladistas portugueses com o verdadeiro sentido estilístico, com ousadia, referenda a autenticidade das interpretações pianísticas, tão criticadas nas décadas posteriores, críticas hoje basicamente estioladas.

O ilustre musicólogo francês François Lesure, recentemente falecido, observaria em texto de apresentação da integral para clavecin de JeanPhilippe Rameau - álbum duplo de CDs lançado em 2000 pelo selo belga De Rode Pomp, piano J.E.Martins -: "O tempo do Barroco integrista passou, o uso dos instrumentos de época deixou de ser um dogma ao qual os músicos são obrigados a aderir sob pena de serem tratados de heréticos. Um dos maiores biógrafos de Rameau - Cuthbert Girdlestone - defendeu com força a idéia de que a música de Rameau 'ganha ao ser transferida para o piano' e que sua escrita encontra neste instrumento, de uma melhor maneira, o seu dinamismo".

Voltando-se ao final do século XVIII, constata-se que entre os anos 1798-1799, dez anos após a Revolução Francesa, desaparecem as classes de cravo do Conservatório de Paris, sendo que são criadas pela mesma Instituição oficial dez classes de piano-forte. O clavecin, que teve o grande esplendor na realeza, devido ao paradigma que representava um dos símbolos musicais da nobreza, desaparecerá, assim como tantos outros elementos simbólico-monárquicos.

A constatação seria clara. Tornar-se-ia fato consumado. Poder-se-ia acrescentar ter sido o século XIX o século do silêncio para o cravo instrumento e a paradoxal aclamação crescente do repertório a ele destinado, inicialmente interpretado ao pianoforte e, mais tarde, ao piano. A transição dos séculos é marcada igualmente por dois fatores consequentes. Os construtores de pianofortes aperfeiçoam rapidamente o mecanismo dos instrumentos e, sob outro aspecto, ainda proliferavam, nessa fase intermediária, métodos destinados ao cravo e ao pianoforte, mesmo aquele já tendo sofrido a ação do cutelo. Este último fato é relevante e mostrará que todo o legado inicial técnico-pianístico vem do cravo e terá o seu desenvolvimento à medida em que os pianos que sucederão os pianofortes se robustecem.

O século XIX ratificaria as certezas do novo quadro geomusical, doravante expandido aos países da Europa Ocidental. Os compositores que resistiram ao tempo através da qualidade escreveriam doravante para o piano, instrumento triunfante. $\mathrm{O}$ desaparecimento oficial do cravo e as 
transformações rápidas do pianoforte em direção ao piano moderno, assim como as salas maiores onde a música orquestral e instrumental eram interpretadas, agiram gradualmente sobre a própria criação. A ebulição constante repertorial fazia-se sentir. Contudo, o repertório escrito para cravo, agora interpretado ao piano, teve essa transferência basicamente sem traumas; poder-se-ia dizer, naturalmente. $\mathrm{O}$ fator ideológico pareceria, a partir do aprendizado do repertório cravístico pelos pianistas, absolutamente esquecido.

Se observada for a linha evolutiva do técnico-pianístico durante o século XIX, independentemente da trajetória das formas estruturais, verifica-se que a base parte da técnica consagrada dos cinco dedos, digital, indisfarçável, soberana. E esta é herança cravística. A evolução do piano instrumento propiciaria aos compositores enriquecerem o técnico-pianístico a partir da ampliação da extensão do teclado e do fortalecimento da máquina piano. Considerando-se o aspecto artesanal da construção dos diferentes instrumentos da família dos cravos, verifica-se que o grande passo no século XIX foi dado graças à indústria do aço, permitindo o aperfeiçoamento do piano. Toda a estrutura em metal tornou-se mais resistente, podendo suportar a enorme tensão de cordas maiores, cruzadas e robustecidas. Sob outra égide, a tábua harmônica seria reformulada. Se a sonoridade obviamente se amplia, atende-se igualmente a outro chamamento, ou seja, salas maiores. Contudo, frise-se, jamais a técnica dos cinco dedos foi abandonada, apesar de recursos inimagináveis terem sido acrescidos ao técnico-pianístico.

O silêncio do cravo no século XIX representaria, pois, de maneira até contraditória, a divulgação do repertório cravístico ao piano. Este conviviria, sem conflitos aparentes, com a avalanche criativo-pianística empreendida de Beethoven a Debussy, passando do virtuosismo o mais exacerbado ao mais introspectivo subjetivismo. E como se processaria a continuação desse repertório cravístico executado no instrumento soberano do século XIX, o piano? Através da tradição.

Walter Benjamin, em $O$ Narrador, pondera que as lendas se perpetuaram através da oralidade. Viajantes e marinheiros narravam histórias ouvidas, perpetradas através da atenção e da posterior propagação pelos ouvintes atentos. Poder-se-ia dizer que o mesmo procedimento, em outro contexto, aconteceria no ensino de um conhecimento. Seria fácil entender que todo o repertório escrito para cravo, clavecin, clavicembalo, harpsichord, com naturalidade, recordemos, incorpora-se definitivamente, e de maneira a menos traumática, ao conhecimento dos pianofortistas, precursores dos 
pianistas. Verifica-se, pois, que não há, em momento algum, curto período que seja, a interrupção do transmitir ensinamentos do repertório cravístico, agora realizado pelos professores e alunos de pianoforte. Outras razões apenas dimensionam essa transmissão. Em sendo o repertório aludido a origem original dos primeiros ensinamentos transferidos doravante aos pianofortistas, observa-se, sob outra égide, que relatos históricos numerosos evidenciam a profunda admiração de Mozart, Beethoven, Czerny, Chopin, Schumann, Liszt pela obra de J.S.Bach e, tardiamente, de Saint-Saëns e Debussy pela criação dos cravistas franceses, ou ainda, de Isaac Albeniz pelas Sonatas de Domenico Scarlatti. Considere-se, in addendo, que a maioria dos autores mencionados deixou frases entusiásticas a respeito dos cravistas, sobretudo sobre Bach e o Cravo Bem Temperado. Os compositores consagrados, preferencialmente os que viveram a transição dos séculos XVIII e XIX, incluindo-se entre eles compositores que pensaram os Estudos básicos para o pianoforte, como Muzio Clementi (1752-1832), Johann Baptist Cramer (1771-1858), Carl Czerny (1791-1857), legaram aos pósteros a configuração básica digital, aquela rotineiramente entendida como técnica dos cinco dedos, já tão bem explicitada em L'Art de Toucher le Clavecin (1716) de François Couperin. $\Lambda$ inalienável técnica dos cinco dedos, perene, herança natural, seria a base da edificação técnico-pianística.

A oralidade aludida anteriormente transmitiria às gerações, através da voz professoral, não apenas a maneira de se interpretar o repertório originalmente para cravo, mas as modificações dessa interpretação motivadas pelas sucessivas ampliações do universo que leva até ao virtuosismo. Ao longo do século XIX e basicamente durante a primeira metade do século $\mathrm{XX}$, parte considerável dos pianistas iniciava seus recitais interpretando determinado autor que compusera para cravo. Liszt e Isaac Albéniz, em épocas diferentes, tocaram Sonatas de Scarlatti publicamente, Saint-Saëns fez o mesmo com obras de Rameau. $\Lambda$ oralidade teria sido responsável pela aplicação, sob limites, de aquisições do romantismo, como problemas ligados à dinâmica, à agógica e à acentuação.

Seria possível acreditar que a virtuosidade levando os tempi a índices extremos nas criações de Liszt, Chopin, Alkan mais precisamente, teria influído num todo relacionado aos andamentos rápidos do repertório cravístico executado ao piano. Dir-se-ia que a torrente contagiaria esse repertório e a oralidade não ficaria estranha a essas modificações, incorporadas doravante à tradição. 
$\mathrm{O}$ argumento dessa oralidade que sedimenta a tradição pode ser justificado pela formação de um estilo pianístico do repertório cravístico. Considerando-se que a obra de Beethoven, Schubert, Chopin, Liszt, Schumann e de tantos outros, teve a manutenção de uma tradição interpretativa graças a essa oralidade - o que faz com que intérpretes mantenham as suas individualidades essenciais, conservando todavia a estrutura "óssea" da criação - observa-se igualmente que as diferenças de andamento e de estilo pouco variam entre os pianistas. Um exemplo claro é o Concerto para piano e orquestra. Os pianistas das mais diferentes escolas espalhadas pelo mundo, ao se apresentarem, raramente trazem problemas para regente ou orquestra, devido a esse estilo geral, tido como um consenso a respeito das obras. A oralidade professoral, a apresentação pública do intérprete e a recepção auditiva soberana do público das salas de concerto corroboram a sedimentação do estilo.

Exatamente o mesmo fenômeno se dá ao entendermos o repertório cravístico executado ao piano. Desde os primórdios da gravação, no início do século XX, há registros ao piano de obras gravadas, escritas originalmente para cravo. No todo, os tempi dos pianistas, assim como as concepções da forma ou a aplicação agógica, dinâmica ou de articulação, são mantidos basicamente nas fronteiras da manutenção estilística, entendendo-se, frise-se, as diferenças de personalidade de cada pianista, ou mesmo as transformações do gosto de época. Contudo, trata-se de um mesmo princípio que abarca o repertório cravístico e todo o grande repertório para piano escrito durante o século XIX. Gravações destes últimos 50 anos apresentam Wilhelm Backhaus ou Edwin Fischer interpretando J.S.Bach; Marcelle Meyer registrando Couperin, Rameau e Scarlatti; Wladimir Horowitz executando Scarlatti ou Felicja Blumental apresentando Seixas ao piano em concepções, mantidas as individualidades, bem próximas de uma identidade encontrada nos pianistas que freqüentam, hoje, esse repertório específico.

Ao se entender essa trajetória ininterrupta da tradição, poder-se-ia deduzir que o silêncio de um século da prática do repertório cravístico em seus instrumentos originais interrompeu a transmissão oral do magister durante esse longo período, o que tornaria a tradição irremediavelmente perdida, pois sem continuidade sonora e auditiva. Quando, na passagem dos séculos XIX e XX, o cravo é redescoberto, revivido, e volta à cena tornando-se lustros após igualmente triunfante, os pesquisadores tiveram de buscar as fontes escritas, partituras e textos, reconstituindo sonoramente o hipotético. Por motivos óbvios, os cravistas do século XX distanciaram-se 
ao máximo de qualquer resquício da única tradição existente, a pianística. Como as pesquisas se desenvolveram em vários países de sólida tradição voltada aos estudos aprofundados, teorias múltiplas surgiram quanto à interpretação do repertório em seu instrumento original, o que resultou numa proliferação de idéias em que seus mentores acreditam, mas que tornam o repertório aludido rigorosamente instável quanto aos tempi, agógica, dinâmica e articulação. Ou seja, se graças à tradição há uma básica unidade na execução desse repertório ao piano, nada mais diferente do que se ouvir dois cravistas formados em escolas geograficamente distantes executando o referido acervo. Não se trata de juízo de valor, pois cravo e piano têm valores distintos, soberanos, inalienáveis e extraordinários. Sob um outro olhar, a redescoberta do cravo teve mais um aspecto meritório: o aprofundamento visando às edições críticas de todo o repertório. Ao buscar junto às fontes essenciais os elementos necessários para a reconstituição de um estilo cravístico, mais acentuadamente nas últimas décadas, cravistas com sólida base voltada à pesquisa debruçaram-se sobre toda essa documentação e realizaram edições críticas do maior mérito. Citaríamos, como exemplos: Macário Santiago Kastner e a obra para teclado de Carlos Seixas, Alessandro Longo e mais aprofundadamente Ralph Kirkpatrick em relação à produção de D. Scarlatti, Kenneth Gilbert e as Pièces de clavecin de J.-Ph. Rameau, sem nos esquecermos das edições urtext da Casa Henle Verlag concernentes à obra de J.S.Bach. Não foram os pianistas que realizaram essas edições, pois eles se estruturaram nessa longa tradição oral e sonora, mas, de maneira até paradoxal, beneficiaram-se ao estudar as edições críticas, doravante muito mais confiáveis. Quanto a Carlos Seixas, dois outros musicólogos, não pianistas, aprofundaram-se em sua obra para instrumentos de tecla, os organistas Gerhard Doderer e sobremaneira João Vaz que está a preparar, juntamente com o musicólogo João Pedro Alvarenga, a edição crítica da opera omnia para teclado do compositor coimbrão e que deverá ser publicada pela Fundação Gulbenkian em 2006.

Como pensar Carlos Seixas ao piano ${ }^{(1)}$ ? A redescoberta empreendida por Macário Santiago Kastner e a afirmação deste quanto à qualidade

(1) As Sonatas mencionadas foram editadas pela Fundação Calouste Gulbenkian, Coleção Portugaliac Musica em 1980 e 1992, sendo 25 e 80 Sonatas respectivamente. A título de exemplificação mais direta, pertencem ao programa apresentado no dia 3 de Junho na Biblioteca Joanina, delc constando 15 Sonatas de Carlos Seixas, c também integram o álbum duplo de CDs contendo 23 Sonatas, lançado pelo selo belga De Rode Pomp em 2004 - pianoJ. E. Martins. 
interpretativa da pianista Felicja Blumental relacionada às Sonatas de Seixas levam-nos a diversas possibilidades. Ouvindo-se as interpretações excelentes da pianista polonesa, pode-se observar que Blumental, por analogia, pensou na obra cravística em geral, Domenico Scarlatti bem em particular. A clareza da execução, os tempi rápidos entendidos nessa visão pianístico-virtuosística da produção de Scarlatti, dão às interpretações da pianista essa verve scarlattiana, mas havendo um sentido amplo da tecladística de Carlos Seixas. Seria possível supor que essa compreensão tenha maravilhado Kastner ao verificar, através dos dedos voltados à virtuosidade e à elegância dos contornos fraseológicos realizados pela pianista, um outro extraordinário valor inerente na obra de Seixas, não se descartando igualmente a possibilidade do musicólogo ter pensado a comparação qualitativa entre Scarlatti e Seixas, entendendo-se o conhecimento prévio de Kastner quanto às interpretações notáveis de alguns pianistas da obra do compositor napolitano. Frise-se que o ilustre pesquisador partira das fontes manuscritas realizadas por copistas e que, como cravista, ao executar as mesmas obras, devido aos próprios recursos do instrumento, e às tendências estilísticas reconstituídas, concebera andamentos mais cômodos. $\mathrm{E}$ pareceria não haver muitas dúvidas de que, em determinado sentido, a virtuosidade pode chegar a éblouir o ouvinte, o que, numa inteligência privilegiada como a de Kastner, pareceria ter acontecido, no caso da brilhante interpretação de Blumental.

Teríamos como conseqüência que Carlos Seixas ao piano, recordemos, apesar da redescoberta relativamente recente na primeira metade do século $\mathrm{XX}$, teria se beneficiado, por analogia, de toda a tradição que acompanhou o repertório cravístico do pianoforte ao piano.

As Sonatas para tecla de Carlos Seixas apresentam certa desigualdade, devido inclusive às várias categorias de alunos que orientou, do aprendiz menos capacitado a alguns que teriam certamente méritos como intérpretes. Ao se pensar em Carlos Seixas, é sempre lembrado um determinado aspecto tardio de sua criação, devido ao fato de ter nascido cerca de vinte anos após os grandes compositores para tecla já mencionados. Contudo, frise-se, seria bom lembrar que Seixas morre em 1742, sendo que dois anos após Johan Sebastian Bach escreveria o segundo livro do Cravo Bem Temperado e, em 1747, Jean-Philippe Rameau, La Dauphine. Esses exemplos dão o sentido da coetaneidade na obra do compositor conimbricense.

Nessa imensa analogia que se estende à interpretação dos autores que compuseram para cravo na primeira metade do século XVIII, guardando-se 
as distintas diferenças estilísticas entre J.S. Bach, J.-Ph. Rameau e D. Scarlatti, pode-se verificar que a obra de Seixas se diferencia por tipicidades que vão do talento inerente do compositor ao aspecto geográfico, incluindo-se, neste, aspectos que poderiam estar ligados à índole lusíada. Seixas, como todo grande autor que se diferencia pela qualidade, tem um idiomático técnicotecladístico pessoal, inerente só a ele. $\mathrm{A}$ idéia que impulsiona a criação e que por sua vez transmite a obra acabada para o papel pautado é única. Conhecendo-se Seixas, sabe-se que é Seixas. Há aquilo que podemos considerar como a impressão digital de um autor de mérito. A tipicidade é só dele.

Entendendo-se que a idéia musical é o resultado de tantos fatores influentes, que vão de todo um acervo cultural adquirido ao longo da trajetória, assim como do olhar e dos ouvidos atentos àquilo que interessa ao compositor, tornar-se-ia compreensível que a obra feita sofra esses impactos. Acrescentando-se o fato de Seixas ter sido um intérprete respeitado, chega-se à escrita técnico-tecladística, diferente da estabelecida por Domenico Scarlatti para os seus dedos e para aqueles de sua discípula real e privilegiada cravista, Infanta Maria Bárbara. Pareceria plausível considerar que muitas das passagens as mais complexas na obra para instrumentos de tecla de Carlos Seixas possam ter sido escritas para os seus dedos e não para aqueles de seus alunos de níveis irregulares. Essa particularidade, quando das dificuldades técnico-tecladísticas em sua obra, poderia explicar a complexidade de muitas dessas passagens, que não resultam necessariamente naturais, entendendo-se por natural uma passagem que logo é captada pelos dedos, fluindo com facilidade. Após a partida de Scarlatti, Seixas teria um diálogo à altura? Não teria pois estabelecido em muitas Sonatas rápidas um código próprio, que para ele funcionava muito bem? $\Lambda$ qualidade de uma escrita que servisse aos virtuoses basicamente é uma das identidades em Scarlatti. Dir-se-ia que, na obra do compositor napolitano, a escrita técnico-tecladística tem a adequação direta, adaptando-se aos dedos com maior naturalidade, comparando-se à de Seixas. Esse dado não implicaria que sonoramente a escrita de Carlos Seixas tenha uma consequência menos favorável, pois resulta, na realidade, no nível do que de melhor se escreveu para cravo.

Acreditamos que a obra para instrumentos de tecla de Seixas tenha uma adequação plena ao piano, mercê de qualidades inerentes a este. Independentemente dos aspectos já aludidos, que contagiaram a partir do início do século XIX todo o repertório para cravo, no qual os tempi já citados, que 
ao correr do século sofreram a influência de outros tempi românticos mais acelerados, observa-se que alguns outros fatores aplicáveis nas obras dos cravistas interpretadas ao piano poderiam ter uma melhor adaptação neste instrumento, sobremaneira na obra de Carlos Seixas. Poderíamos considerar como essenciais dois aspectos observados por Kastner em seu livro Carlos de Seixas de 1947: a ornamentação mais discreta, comparando-se à de seus ilustres coevos, devido ao desconhecimento do compositor português da rica ornamentação dos estrangeiros e a preponderância bem acentuada da mão direita sobre a mão esquerda, característica, segundo Kastner, das Sonatas de Scarlatti compostas em Portugal. Se considerarmos outros sinais ou expressões, fixados ou não na partitura, mas que seriam fundamentais na interpretação no romantismo, poderíamos incluir a própria flutuação de andamentos, que encontraria no rubato um avatar que se expandiria como um leque nas interpretações das obras dos autores do século XIX. O rubato teria influência, igualmente, na interpretação do repertório cravístico interpretado ao piano.

Ao mencionarmos os fatores geopolíticos, gostaríamos de salientar que entendemos a obra de Seixas como única e diferenciada daquela produzida por seus coetâneos, inclusive Scarlatti. Num outro contexto geográfico, na Espanha o cravo não teria sido cultivado à altura durante o século XVIII, sendo que Joaquin Nin chega a afirmar em 1925 que os músicos espanhóis do período mediocremente cultivaram o cravo. Contudo, pianistas têm frequentado as obras de compositores como Padre Antonio Soler (1729-1783) e Mateo Albeniz (1760?-1831) mais intensamente. Estes autores são bem posteriores a Carlos Seixas, sendo que Soler escreveria para cravo e posteriormente para pianoforte, verificando-se, pois, que a produção para teclado de Carlos Seixas é ímpar na Península Ibérica nesse período.

$\mathrm{Na}$ obra específica do compositor coimbrão há determinados ingredientes que pertencem à alma portuguesa, só a ela, fato claramente identificado nos andamentos bem lentos. Não estaria Seixas longe do que ouve ou sente pelas ruas lisboetas. Sob outra égide, determinadas terminações em andamentos rápidos poderiam ser entendidas como características da música portuguesa não erudita, como nas Sonatas n. ${ }^{\circ} 46 \mathrm{em}$ Sol maior, n. ${ }^{\circ} 68$ em Lá menor e muitas outras. A somatória desses atributos faz com que, ao piano, novas possibilidades possam ser aproveitadas.

Quanto às Sonatas de Seixas, Kastner refere-se à mão direita preponderando sobre a esquerda. Pode, contudo, entender-se hoje, ao 
piano, a presença de baixos caminhantes executados pela mão esquerda, muitas vezes, verdadeiros centro tonais, o que dá às Sonatas tipificadas uma outra dimensão, ou seja, as fundamentais passam a ter todas as possibilidades da dinâmica e da acentuação. Sempre é bom lembrar conceitos do Traité de l'Harmonie réduite à ses principes naturels de Jean-Philippe Rameau e que data de 1722, e que em seu artigo primeiro do primeiro livro reitera a importância da fundamental. Em textos outros Rameau ratificará essa posição. Para o piano moderno, a interpretação torna-se, pois, plena de possibilidades sonoras, dimensionando e valorizando os grandes desenhos da mão direita. São muitos os exemplos em que essa prática na prevalência aparente da mão direita mostra-se evidente e teríamos de citar algumas dezenas de Sonatas de Seixas, o que não seria viável no espaço reservado à presente conferência. Contudo, a monumental Sonata n. ${ }^{\circ} 10$ em Dó maior, com seus 390 compassos, Sonata plena de alternativas, rigorosamente virtuosística, é típica, e nela Seixas emprega uma série de atributos técnico-tecladísticos como escalas, arpejos, rápidos movimentos de terças, técnica paralela ou não dos cinco dedos nas duas mãos, assim como os baixos caminhantes, modulantes, por vezes cromáticos, dando toda a estrutura cantante às flexibilizações da frase. $\Lambda$ qualidade única da Sonata $n .^{\circ} 10$ daria bem a dimensão do sentido do amplo existente em Seixas, que em contrapartida escreve uma dramática Sonata n. ${ }^{\circ} 24$ em Ré menor de apenas 29 compassos, Sonata esta que bem pode antever determinadas aberturas mozarteanas tão posteriores, e na qual o drama é expressado pelos baixos em semínimas sustentando uma linha ininterrupta e diversificada de semicolcheias da mão direita. Se nas obras mencionadas o papel das fundamentais é essencial e Kastner, em tantas oportunidades, apresenta-as oitavadas, há que se considerar o papel preponderante que, ao piano, terá o pedal. Acreditamos que o mesmo não pode ser entendido como pedalização plena, mas, no caso de Seixas particularmente, há que se ter a consciência de um emprego flexibilizado que recorrerá aos múltiplos matizes representados pelas alternativas $1 / 4,1 / 2,3 / 4$ de pedal, sempre tendo-se em mente as ressonâncias proporcionadas pelos baixos, assim como pela condução melódica, esta, tantas vezes configurada por passagens rápidas da mão direita. Chamam a atenção essas fundamentais seixianas, que basicamente ignoram um simples desempenho acompanhador. Em muitos momentos, são elas que conduzem, no estrito sentido, o caminhar fluente e rápido, quando é o caso, das passagens da mão direita. Um diálogo nítido 
pode ser observado na esplêndida Sonata $78 \mathrm{em} \mathrm{Si} \mathrm{bemol} \mathrm{maior,} \mathrm{entre} \mathrm{os}$ compassos 70-75, em que a mão direita, no desenho ininterrupto de semicolcheias, tem a imitação instantânea das oitavas em colcheias da mão esquerda. Para o pianista, em muitas das passagens em Sonatas de Seixas, há a possibilidade do amplo entendimento do que se convencionou chamar de nota pedal, a criar atmosfera única no todo da passagem, nessa conservação da pedal note, expressa na mão esquerda, inequívoca, apesar das transformações realizadas pela mão direita.

$\Lambda$ variedade das opções empregadas por Seixas, sob outro aspecto, evidencia em muitas das Sonatas a participação ativa das duas mãos, num verdadeiro sentido ambidestro. Como exemplos marcantes há as Sonatas n. ${ }^{\circ}$ 34. em Mi maior, ou a Sonata n. ${ }^{\circ} 27$ em Ré menor e tantas mais. Conhecedor de todos os recursos técnico-tecladísticos, como o emprego das notas repetidas ou do cruzamento das mãos, Seixas demonstra, em Sonatas como as de números 46 e $47 \mathrm{em}$ Sol Maior ou a de n. ${ }^{\circ} 50 \mathrm{em}$ Sol menor, essa freqüência absolutamente à vontade nesses desenhos mais complexos para os dedos.

René Descartes em Abregé de Musique - Compendium Musicae, datado de 1618-19, escrevia sobre o som e a música: Sa fin est de plaire, et d'émouvoir en nous des passions variées, e um século após François Couperin, no prefácio do primeiro livro de Ordres, em 1713, observava: j’aime beaucoup mieux ce qui me touche, que ce qui me surprend. Ao lermos as 105 Sonatas de Seixas, chamou-nos a atenção uma constante que ocorre quase sempre na segunda parte dessas majoritárias sonatas bipartidas, ou seja, uma espécie de "culminância emotiva". Sem entrarmos em pormenores que certamente envolveriam a tão decantada secção áurea, tenderíamos a acreditar tratar-se de uma subjetividade à qual Seixas se inclina, conscientemente ou não, basicamente entre o início da segunda parte dessas sonatas em um movimento - quando basicamente há a modulação em sentido inverso - à secção intermediária desta. Se o intérprete constatou, conscientemente ou não, essas "culminâncias", haveria que se pensar em como tratá-las. Pianisticamente, através de pequenas ou médias flexibilizações agógicas, a causarem uma leve alteração de andamento em um ou no máximo em pouquíssimos compassos. Esse procedimento não caracteriza propriamente um rubato, mas sim o que Claude Debussy tanto utilizou, e que bem denomina cédez, ou seja, a diminuição do andamento, um degrau a menos, diríamos, para logo após retomar-se o andamento inicial. Neste 
caso, não se trata de um ritenuto ou ritardando, mas desse patamar diferenciado no instante do acontecido. Lembremos que esse atributo seria integrante de uma tradição pianística aplicável quando do repertório cravístico.

Girdlestone entende Rameau melhor ao piano, como mencionámos anteriormente. Carlos Seixas ao piano possibilita a escuta de um compositor que em tantos momentos esteve bem a frente de seu tempo histórico. Seria possível entender que o isolamento geográfico, já citado, em que viveu durante toda a vida propiciasse a elaboração "laboratorial" de uma técnica muito pessoal. A falta de contato com outros cravistas de renome e o contato com Domenico Scarlatti durante a estadia deste em Lisboa poderiam, para uma mente privilegiada como a de Seixas, ter sido, para um exímio intérprete que era, o motivo da elaboração livre de formulações técnico-tecladísticas, longe de qualquer crítica, elogio ou censura de possíveis concorrentes à altura. Seria essa criatividade em lidar com os materiais a base segura da grande originalidade da obra para teclado de Carlos Seixas.

Felicja Blumental realizou gravações antológicas da obra de Seixas. Disséramos que o modelo scarlatiano de interpretação estaria presente. Contudo, numa visão hodierna, a modernidade de sua escrita, a antevisão de um tecladismo original e amplo, a utilização racional da movimentação dos baixos, a "aplicação agógica" entre outros atributos, proporcionam ao pianista uma outra compreensão da obra. $\Lambda$ tradição pianística lá está, a leitura - como vimos anteriormente na referência às mutações interpretrativas da execução dos cravistas ao piano nos séculos XIX e XX -, esta, sofreria as conseqüências de outras mutações relacionadas à própria interpretação. Nesse item, incorporemos gosto de época e estilo.

Mais de setenta anos após o redescobrimento, Seixas continua um quase ignoto para os intérpretes e para aqueles que escrevem textos sobre autores e repertórios e que teriam, no mínimo, o dever e a obrigação de um conhecimento descentralizado do eixo dos países que mantêm a "tutela" do que deve ser conhecido ou ouvido. $\Lambda$ ausência de Carlos Seixas é uma lacuna, no mínimo, constrangedora. Será necessário um grande esforço de todos nós, intérpretes e musicólogos, no sentido de divulgar aos quatro cantos a obra do ilustre compositor português.

O que se nos afigura extraordinário e esperançoso é haver espaço suficiente para o ótimo entendimento da obra de Seixas ao cravo, ao órgão ou ao piano. Os três instrumentos têm vidas independentes e podem 
conviver pacificamente em prol de uma causa maior e única: a difusão da extraordinária produção para teclado do notável Carlos Seixas. Muito bem cuidou a coordenação científica deste Colóquio, na figura do respeitado musicólogo e professor desta Universidade, José Maria Pedrosa Cardoso, da apresentação da obra para teclado de Carlos Seixas em recitais diferenciados, privilegiando os três instrumentos: órgão, cravo e piano. Enquanto não estiver justamente conhecido e interpretado nas principais salas de concerto do mundo, uma falta irreparável estará a ser perpetrada. Será possível entender que o passo a mais proporcionado neste Colóquio seja uma semente da esperança. Portugal tem de quem se orgulhar, e muito, num período em que pontificaram colegas ilustríssimos de Carlos Seixas, como J. S. Bach, G. F. Haëndel, J.-Ph. Rameau e D. Scarlatti, cujas obras não superam muitas das criações do ilustre compositor conimbricense. Comemoremos festivamente o tri-centenário do grande Carlos Seixas. 
(Página deixada propositadamente em branco) 


\section{Série}

\section{Documentos}

Imprensa da Universidade de Coimbra

Coimbra University Press

2004

- U

C • 